\title{
Nursing Students' Views and Experiences Concerning the Use of Mobile Applications in Nursing Education: A Qualitative Study
}

\author{
Ayse Kacaroglu Vicdan (iD $^{1^{*}}$ and Media Subasi Baybuga ${ }^{2}$ \\ ${ }^{1}$ Assistant Professor, Department of Fundamental Nursing, Faculty of Health Sciences, Mugla Sitki Kocman \\ University, Mugla, Turkey \\ ${ }^{2}$ Professor, Department of Public Health Nursing, Faculty of Health Sciences, Mugla Sitki Kocman University, \\ Mugla, Turkey
}

*Corresponding author: Ayse Kacaroglu Vicdan, RN, PhD, Assistant Professor, Department of Fundamental Nursing, Faculty of Health Sciences, Mugla Sitki Kocman University, Mugla, Turkey, Tel: +90-252-211-56-43, Fax: +90-252-211-18-80

\begin{abstract}
Background: Nursing education is a process of education that consists of both theoretical and skill teaching. Mobile applications developed in accordance with smart phones have started to be used in nursing education, for the students to continue to learn outside school and develop their knowledge and skills.
\end{abstract}

Methods: This study was conducted in the Department of Nursing in the Faculty of Health Sciences at a University located in the western region of Turkey between the dates of between May 7, 2019, and May 30, 2019, by using qualitative research design. Qualitative research was planned in order to examine the opinions and experiences of nursing students who used the mobile application. Purposeful sampling method was used in the study.

Results: The findings of the study, the students (45.5\%) indicated that the mobile application prepared was appropriate for their level and the mobile application was adequate for them $(52.3 \%)$. The study also pointed out that nursing students were curious $(75 \%)$ and thought that it would be useful $(31.8 \%)$, were excited $(22.7 \%)$, felt special $(20.5 \%)$, were relaxed $(20.5 \%)$ and felt happy $(27.3 \%)$. The students indicated that they had less stress $(68.2 \%)$, felt enlightened $(90.9 \%)$, felt competent on the subject $(63.6 \%)$ and had more self-confidence (29.5\%) after using the mobile application. All of the nursing students $(100 \%)$ reported that it was necessary to use mobile applications in nursing education.

Conclusion: It was seen that using the mobile application in nursing education increased the students' self-confidence and self-competence, and also reduced their stress. Besides, the students belive that it will be useful to use both standard teaching method in which the instructor lectures and relevant mobile applications together.

\section{Keywords}

Nursing education, Nursing students, Mobile application, Qualitative study

\section{Introduction}

Nursing education is a process of education that consists of both theoretical and skill teaching. Primary purpose of nursing education is to train qualified nurses $[1,2]$. An important part of nursing education consists of psychomotor skill teaching. Psychomotor skill indicates a skill which is performed rapidly, accurately and skilfully [3]. It is expected from nursing students to possess the complete competence in the taught skills $[1,3]$. In the nursing curricula, methods such as expressions, demonstrations, control lists, case scenarios, role plays, videos and simulated/ standardized patients are used for the students to acquire theoretical knowledge and skill [4-7]. Today, mobile phones are also started to be used as an educational tool in nursing education with the developments in mobile technologies $[8,9]$.

Together with the development of mobile technologies in the present day, mobile phones have become an inseparable part of our daily lives [8-10]. Mobile phones have become popular among users as they are portable, multi-purpose, provide a continous accessibility and offer social network services $[9,11]$. The developing information technologies

Citation: Vicdan AK, Baybuga MS (2019) Nursing Students' Views and Experiences Concerning the Use of Mobile Applications in Nursing Education: A Qualitative Study. Int Arch Nurs Health Care 5:137. doi.org/10.23937/2469-5823/1510137

Accepted: December 17, 2019: Published: December 19, 2019

Copyright: (C) 2019 Vicdan AK, et al. This is an open-access article distributed under the terms of the Creative Commons Attribution License, which permits unrestricted use, distribution, and reproduction in any medium, provided the original author and source are credited. 
have facilitated the use of mobile phones in the field of education, as in all other fields [12,13]. Especially mobile applications developed in accordance with smart phones have started to be used in education $[11,13]$. Mobile applications are software that are designed and coded specifically for mobile devices such as smart phones and tablets [14,15]. Mobile applications have also started to be used in nursing education where psychomotor skills are of prime importance, for the students to continue to learn outside school and develop their skills [16-19]. Mobile applications facilitate reaching information, help to learn while having fun and provide the liberty of time and place in learning $[17,18]$.

Considering the studies using mobile applications in nursing education; it is seen that mobile applications increase the students' knowledge and skills $[1,4,11,20$ 24], enhance their self-confidence [23-25], reduce their stress [25], increase their competence $[20,21]$ and enhance their learning motivation [21]. Examining the literature; it is seen that there are mostly quantitative studies evaluating the effectiveness of mobile applications [2,20-24], whereas there is a limited number of qualitative studies revealing the students' views and experiences concerning mobile applications $[18,26]$.

In the literature, it is suggested to include mobile technologies to education in order for students to improve themselves in the fields of theory and skill in nursing education. Due to the easy-accessibility and portability features of mobile technologies, learning activities such as repeating a subject and reinforcing application steps can be maintained outside of the classroom environment $[23,24]$. Students can initiate the learning process whenever and wherever and intervene in the process whenever they desire. Moreover, mobile technologies in nursing education are extremely important in terms of presenting research diversity, the convenience of information retrieval, personal learning, and the possibility of instant feedback and evaluation $[20,24,25]$.

It is required for nursing students to improve themselves by practicing before performing clinical applications without risking the safety of patients and themselves. Additionally, the excessive number of students in the nursing departments, insufficient number of instructors, time restriction and lack of proper laboratory environments prevent students to improve the psychomotor abilities at the desired level $[11,23]$. In nursing education in which psychomotor skills are significant, the use of mobile technologies in terms of maintaining out-of-class learning and improving knowledge and the skills of students would contribute greatly to nursing education $[14,20]$. This study was conducted to determine the nursing students' views and experiences concerning the use of mobile applications in nursing education.

\section{Method}

This study was conducted in the Department of Nursing in the Faculty of Health Sciences at a university located in the western region of Turkey between the dates of May 7, 2019, and May 30, 2019 by using qualitative research design. In the study, a blood pressure mobile application was installed on the android phones of 178 students who were studying in the first grade of the department of nursing. The students were asked to use the installed mobile application between the dates of March - April 2019. Qualitative research was planned in order to examine the opinions and experiences of students who used the mobile application. Purposeful sampling method was used in the study. The purposeful sampling method is a method that is frequently used in qualitative research designs and provides the obtainment of information that was not obtained with other methods without calculating the sample size $[27,28]$. The study was completed with 44 students until the knowledge is started to be repeated at the saturation point.

\section{Data collection tool}

In this study, the data were collected via a semi-structured interview form which was developed by the researchers in accordance with the study objective. The first part of the interview form consists of three questions about age, gender and graduation school. The other part consists of twelve questions about the students' time spent on the internet, purpose of using mobile phone, phone applications, status of using mobile applications during their former education, environments where they use mobile applications, thoughts about the mobile application prepared for nursing education, frequency of using the mobile application, feelings about using the mobile application, problems faced while using the mobile application, feelings (such as self-confidence, stress, self-competence) about the use of the mobile application while applying skill, thoughts about whether to use mobile applications in nursing education or not and suggestions about developing mobile applications in nursing education.

\section{Implementation of the study}

The interviews were conducted in hours when the students and researchers were available, in a room where only the researchers and students were present, using the focus group interview technique via the semi-structured interview form which had been prepared beforehand. Focus group discussion is a significant tool in collecting qualitative data. In this method, the data is obtained from individuals who were chosen purposefully rather than a wider sample group. Focus group discussion is a qualitative method that aims to acquire information about the psychological and socio-cultural features and behaviors that groups perform 
semiconsciously or unconsciously and to learn the underlying causes [29].

The participants were given numerical codes and were asked to sit down without giving their names before the interviews. The students were reminded of the confidentiality of information shared during the interviews. Before the study, they were informed that the interviews would be recorded via recorder and an interviewer would take notes. The moderator and observer introduced themselves before the interviews and then the interviews were conducted. The interviews took approximately 55 minutes and as the answers were satisfying enough, the study was completed in six sessions. Distribution of the number of each interview and participant is as follows; 1 . Interview: Seven participants, 2. Interview: Eight participants, 3. Interview: Eight participants, 4. Interview: Seven participants, 5. Interview: Seven participants, 6. Interview: Seven participants, which makes a total of 44 nursing students.

\section{Data analysis}

In this study, the record content was written down, analyzed with observation notes and deciphered after each interview. The content analysis method was used in analyzing the data. The content analysis aims to attain concepts and relationships that can explain the data collected, to define the data and to reveal the truth that may be hidden within the data. In order to provide internal validity of the qualitative study, the texts of the interviews, codes and reproduced categories were evaluated and confirmed by an expert who was experienced in qualitative studies via expertization, for the purpose of examining the analysis process [27]. The data acquired were expressed with numbers and percentages. The obtained data from the participants were read, significant sentences or statements were underlined and coded by separating into significant sections. Then, six themes were created by classifying the codes with the same meaning. In accordance with the data obtained from the study, main themes were determined under the titles of opinions towards the mobile application, the aim of using the mobile application, the emotions students felt in the mobile application process, the difficulties experienced in the mobile application process, the benefits of the mobile application in nursing education, and the use of the mobile application in nursing education.

\section{Ethical considerations}

In order to conduct the study, an ethical approval was received from Mugla Sitki Kocman University Scientific Researches and Publication Ethics Council (Protocol no: $190088 / 86 / 2019$ ) and a permission from the institution where the study was conducted. In addition, the study purpose was explained to the students who participated in the study and their written consent was received.

\section{Results}

Among the students who participated in the study; $81.8 \%$ are in the age range of $18-19$ years, $72.7 \%$ are

Table 1: Demographic characteristics of the nursing students $(n=44)$.

\begin{tabular}{|l|l|l|}
\hline Demographic Characteristics & n & $\%$ \\
\hline Age & 36 & 81.8 \\
\hline $18-19$ years & 8 & 18.2 \\
\hline$\geq 20$ years & \multicolumn{2}{l|}{} \\
\hline Gender & 32 & 72.7 \\
\hline Female & 12 & 27.3 \\
\hline Male & & \\
\hline Last Graduated School & 30 & 68.2 \\
\hline Anatolian high school & 9 & 20.5 \\
\hline Basic high school & 4 & 9.1 \\
\hline Science high school & 1 & 2.2 \\
\hline University & & \\
\hline
\end{tabular}

Table 2: Distribution of nursing students regarding their mobile phone usage $(n=44)$.

\begin{tabular}{|l|l|l|}
\hline \multicolumn{4}{|c|}{} & $\mathbf{n}$ & $\%$ \\
\hline \multicolumn{2}{|c|}{ Amount of mobile phones are used by the students } \\
\hline 2 - 4 hour & 16 & 36.4 \\
\hline > 5 hour & 28 & 63.6 \\
\hline
\end{tabular}

Average time spent on the internet $4.75 \pm 1.64$ (hour)

(Min: 2 - Max: 12 )

\begin{tabular}{|l|l|l|}
\hline Purpose of mobile phone usage & \multicolumn{2}{l|}{} \\
\hline Social media & 44 & 100.0 \\
\hline Talking & 44 & 100.0 \\
\hline Reading books & 33 & 75.0 \\
\hline Homework & 32 & 72.7 \\
\hline Watching movies & 25 & 56.8 \\
\hline Listening music & 25 & 56.8 \\
\hline Watching videos & 22 & 50.0 \\
\hline Playing games & 15 & 34.1 \\
\hline Messaging & 13 & 29.5 \\
\hline Regularly used mobile applications & & \\
\hline Instagram & 44 & 100.0 \\
\hline WhatsApp & 44 & 100.0 \\
\hline YouTube & 44 & 100.0 \\
\hline Game apps & 26 & 59.1 \\
\hline Music apps & 24 & 54.5 \\
\hline Movies apps & 12 & 27.3 \\
\hline Other educational apps & 6 & 13.6 \\
\hline Shopping apps & 6 & 13.6 \\
\hline Reading apps & 5 & 11.4 \\
\hline Using mobile applcations & & \\
\hline
\end{tabular}

Using mobile applications during their previous education

\begin{tabular}{|l|l|l|}
\hline Yes & 31 & 70.5 \\
\hline No & 13 & 29.5 \\
\hline
\end{tabular}

"The participants reported more than one opinion. 
female and $68.2 \%$ are Anatolian high school graduates (Table 1). $63.6 \%$ of the students spend five hours and above on the internet. $100 \%$ of the participants use their smart phones to talk and use social media, $75 \%$ to read books, $72.7 \%$ to do their homework, $56.8 \%$ to watch movies, $56.8 \%$ to listen to music and $50 \%$ to watch videos. $100 \%$ of the students have Instagram, 100\% WhatsApp, 100\% YouTube, 59.1\% game applications and $54.5 \%$ music applications on their smart phones. $95.5 \%$ of the students use their mobile phones everytime and everywhere and $70.5 \%$ had used mobile applications before their nursing education (Table 2).
Theme 1: The opinions towards the mobile application

The nursing students who participated in the study indicated that the mobile application prepared was appropriate for their level (20 participants, 45.5\%), the mobile application was adequate ( 23 participants, $52.2 \%)$ and the colors of the mobile application were vivid and convenient (18 participants, $40.9 \%$ ); whereas seven participants (15.9\%) stated that the mobile application was too colorful. In addition, $11(25 \%)$ stressed the necessity of notifications to remind to go online in the mobile application and $14(31.8 \%)$ participants

Table 3: Experiences and views of the nursing students regarding the mobile application prepared for nurse education $(\mathrm{n}=44)$.

Experiences and views regarding the mobile application

Thoughts about the mobile application prepared for skill teaching

Suitable for my level

Adequate

The colors of the mobile application were vivid and convenient

The mobile application was too colorful

Notifications reminding one to use mobile application should be added

Evaluation questions should be added

Aim of the using the mobile application*

To learn the subject

To prepare to the exams

Before the training at the hospital

Before performing the application in the school's skill laboratory

To do practice

To be prepared for the course

Feelings before and during using the mobile application*

\begin{tabular}{|c|c|c|}
\hline Curious & 33 & 75.0 \\
\hline Useful & 14 & 31.8 \\
\hline Excited & 10 & 22.7 \\
\hline Feeling special & 9 & 20.5 \\
\hline Relaxed & 10 & 22.7 \\
\hline Feeling happy & 12 & 27.3 \\
\hline Having prejudices against the mobile application & 5 & 11.4 \\
\hline Hesitant & 3 & 6.8 \\
\hline \multicolumn{3}{|l|}{ Were any problems experienced while using the mobile application? } \\
\hline Yes & 40 & 90.9 \\
\hline No & 4 & 9.1 \\
\hline \multicolumn{3}{|l|}{ Fellings when applying skills after using the mobile appication* } \\
\hline Knowledgeable & 40 & 90.9 \\
\hline Enough & 28 & 63.6 \\
\hline More self-confidence & 13 & 29.5 \\
\hline Less stressful & 30 & 68.2 \\
\hline \multicolumn{3}{|c|}{ Suggestions about developing mobile applications used in nursing education* } \\
\hline They should have reminder/alert systems & 44 & 100.0 \\
\hline They should be supported by eveluation questions & 44 & 100.0 \\
\hline They should be include more nursing topics (IM injection, IV injection etc.) & 44 & 100.0 \\
\hline
\end{tabular}

They should be include more nursing topics (IM injection, IV injection etc.)

The participant reported more than one opinion.

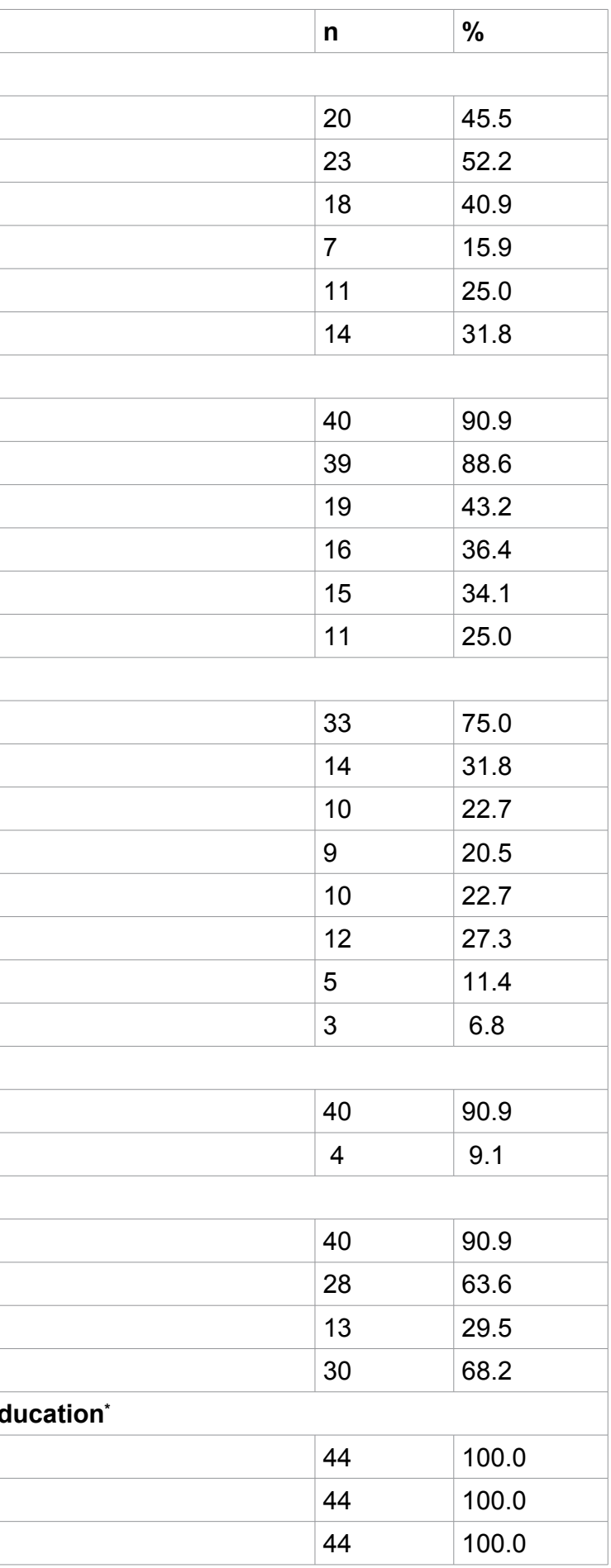


mentioned the need for evaluation questions (Table 3). Some of the participants' views on their opinions about the mobile application prepared for nursing education are as follows:

"...it was easy to download for android phones... it was easier to use than I expected...the subjects were summarized and were appropriate for our level... videos in other subjects can be added..." (P15, Age 19, Female, 2. Interview)

"...there was no lack of theoretical knowledge, but I needed eye contact with a teacher..." (P19, Age 20, Female, 3. Interview)

"...the application was good. the book contained too much information about the subject... the mobile application, on the other hand, only contained information that we needed, which was good enough..." (P34, Age 18, Female, 5. Interview).

\section{Theme 2: The aim of using the mobile application}

In the study, it was determined that the students who were interviewed used the mobile application to learn the subject (40 participants, 90.9\%), to prepare to the exams (39 participants, $88.6 \%$ ), before the training at the hospital (19 participants, $43.2 \%$ ), before performing the application in the school's skill laboratory (16 participants, $36.4 \%$ ), to do practice (15 participants, $34.1 \%$ ) and to be prepared for the course (11 participants, $25 \%$ ) (Table 3). Some of the participants' views on their intended use of the mobile application prepared for nursing education are as follows;

"...I was using it very often at first... but it was more useful around the exam period..." (P39, Age 18, Female, 6. Interview)

"...at first, I used it very often to learn the subject... when I thought that I had learned, I began to use it less often... I checked it again and again around the exam period..." (P41, Age 19, Female, 6. Interview)

"...। used it before the training... I use it before the exams..." (P28, Age 18, Female, 4. Interview.

Theme 3: The emotions students felt in the mobile application process

The students who participated in the study indicated that they were curious (33 participants, 75\%), thought that it would be useful (14 participants, $31.8 \%$ ), were excited (10 participants, $22.7 \%$ ), felt special (9 participants, 20.5\%), were relaxed (10 participants, $22.7 \%$ ) and felt happy (12 participants, $27.3 \%)$ before and while using the mobile application; whereas five participants $(11.4 \%)$ stated that they had prejudices against the mobile application when they first heard it and three participants (6.8\%) stated that they were hesitant that the application would take up too much space in their phones (Table 3). Some of the participants' views on their feelings about the mobile application prepared for nursing education are as follows;

"...it was really good to be able to attain the course subject outside course hours... it made me learn better... I got happy..." (P3, Age 19, Female, 1. Interview)

"...I liked that it was something new and I was also happy to learn new things... I had encountered such an application for the first time in my life..." (P13, Age 19, Male, 2. Interview)

"...I felt relieved... as the classroom was very crowded, I was too shy to ask questions... the application made me feel safe..." (P19, Age 18, Female, 3. Interview)

"...at first I thought it would not be effective at all... then I changed my mind... it increased my knowledge and skills..." (P20, Age 20, Male, 4. Interview).

Theme 4: The difficulties experienced in the mobile application process

40 of the participants (90.9\%) had no problem with downloading the mobile application, having internet outages and running out of battery; whereas four participants $(9.1 \%)$ stated that they had problems while downloading the mobile application and received support (Table 3). Some of the participants' views on their problems while downloading the mobile application prepared for nursing education are as follows;

"...it was really advantageous to use the application without internet..." (P4, Age 19, Female, 1. Interview)

"...I had a problem only while downloading it... I called my teacher and we downloaded it once again..." (P24, Age 19, Female, 5. Interview).

Theme 5: The benefits of the mobile application in nursing education

The students indicated that they had less stress $(30$ participants, $68.2 \%$ ), felt enlightened (40 participants, $90.9 \%$ ), felt competent on the subject (28 participants, $63.3 \%$ ) and had more self-confidence (13 participants, 29.5\%) while applying the skill after using the mobile application (Table 3). Some of the opinions of students towards the benefits of the mobile application in nursing education;

"...I followed the mobile application... although I missed the course while the subject was being taught, my knowledge still increased... I felt competent and had no stress at all..." (P17, Age 21, Male, 3. Interview)

"...I felt more enlightened and competent... I had less stress while using the application..." (P40, Age 19, Female, 6. Interview)

"... I had the chance to watch the video again and again, which reduced my stress... I felt enlightened and more confident... I had a feeling that I could do it..." (P15, Age 19, Female, 3. Interview). 


\section{Theme 6: The use of the mobile application in nurs-} ing education

All of the students who participated in the study indicated that it was necessary to use mobile applications in nursing education. In addition, they all stated that rather than alone, it would be more useful to perform the mobile application integratedly with expression, demonstration and laboratory applications used in nursing education (Table 3). Some of the opinions of participants towards the use of the mobile application in nursing education are as follows;

"...It would be good for all applied courses... we don't want to read the school boks... it is difficult to carry the books all the time... the mobile application would be good, because I have my phone with me all the time..." (P17, Age 21, Male, 3. Interview)

"...the mobile application should be downloaded before the theoretical course so that I can be prepared to the course... I can practise it whenever I wish to... there should be both the teacher and the mobile application... the classroom environment is good for me to learn... it is better in the classroom environment (jokes, laughters)..." (P43, Age 19, Female, 6. Interview)

"...the mobile application should be used in nursing education... videos are always more effective... first the teacher should teach and then we should practise on the application... it is better to watch videos at home..." (P24, Age 19, Female, 4. Interview).

In addition, concerning the development of the mobile application; all of the students suggested that it was necessary to have a reminder notification/warning system, to support the mobile application with relevant evaluation questions and to prepare mobile applications for other nursing skills as well (Table 3). Some of the participants' suggestions for mobile applications to be prepared for nursing education are as follows;

"...the questions in the mobile application could be online... the teacher could evaluate us from there..." (P11, Age 19, Male, 2. Interview)

"...new subjects should be added... the videos should be uploaded in parallel with weekly subjects... we cannot see all the materials in the class... it should be supported with photos". (P33, Age 19, Female, 5. Interview)

"...the application should also be available for other skills... there should be questions with which we can test ourselves... there should be a reminder for certain times... the visual content can be enhanced..." (P38, Age 18, Male, 6. Interview).

\section{Discussion}

The findings obtained as a result of the qualitative research which was conducted in order to determine the opinions and experiences of nursing students towards the use of the mobile application in nursing education were discussed in accordance with the literature.

As a result of the focus group interviews conducted in the study, it was revealed that more than half of the nursing students spent more than five hours on the internet on their mobile phones and used their phones to talk, socialize, have fun and do their homework. It was determined that all of the participants had mobile applications such as Instagram, WhatsApp and YouTube on their phones and almost all of them used their phones everytime and everywhere (Table 2). In the study conducted by Alsayed, et al. [9] with 135 nursing students in the literature, it was found that $92.6 \%$ of the students would certainly check their mobile phones first when they woke up in the morning, $94.8 \%$ before going to bed every night and $94.8 \%$ used their phones everywhere. In the study conducted by Damor, et al. [30] with medical students, it was determined that $99.7 \%$ of the students used mobile phones, $98.1 \%$ went online on their mobile phones and $53.6 \%$ spent $4-6$ hours on the internet. In the same study, it was also found that $65.2 \%$ of the students used their phones to go online on social media. In the study conducted by Slaih, et al. [31] with 918 university students, it was seen that the participants spent more than five hours on the internet on average, $30.7 \%$ would check their phones every 20 minutes and nearly $21 \%$ would check them every 10 minutes once or more, $93.1 \%$ used their phones to talk, $90.1 \%$ to use social media, $81.3 \%$ to listen to music and $49.6 \%$ to play games. As is seen in this study and in other studies, the university students use their mobile phones for many purposes such as talking, socializing and having fun and spend most of their time using their phones within the day. Today, mobile phones have become a tool for every age group, especially the youth to socialize and have fun beyond communication. These findings indicate that mobile phones can be used as an educational instrument with the purpose of supporting the continuation of nursing education outside of school.

In the study, a part of the students stated that the mobile application prepared was appropriate for their level and the colors within the content of the mobile application were vivid and convenient; some of them complained that the mobile application was too colorful (Table 3 ). This situation signifies that it is important to prepare the mobile applications for nursing education according to the level of students and to take the opinions of students.

Regarding the contributions of the mobile application in nursing education; their decreased stress, increased knowledge, they felt more competent and confident (Table 3). In similar relevant studies conducted with nursing students using mobile applications and videos, it was seen that the students' 
knowledge and skills increased [1,4,11,20-24]. Additionally, it was found that using mobile technologies in nursing education increased the students' self-competence [2,23-25], self-confidence [2,21,24], satisfaction [21,23], motivation [21], critical thinking [32] and communication [1,31] and reduced their stress [25]. Findings of the literature and this study emphasize that using mobile technologies in nursing education increases the students' knowledge, skills, motivation, self-confidence and self-competence and reduces their stress level. Thus, it is an inevitable fact that including mobile technologies in nursing education in the nursing curricula will make an important contribution to training qualified nurses of the future.

Concerning the using of the mobile application in nursing education; all of the students reported that it was necessary to have a reminder notification/warning system, to support the mobile application with relevant evaluation questions and to prepare mobile applications for other nursing topics as well (Table 3 ). In the focus group interviews conducted by $\mathrm{Li}$, et al. [26] with 20 nursing students, the students offered that it was necessary to have a student response system and an online evaluation form for student - instructor interaction and to update the videos continuously. In the study conducted by Lee, et al. [21], Kang and Suh [24] concerning a mobile application that they developed for nursing students, the students reported that the mobile application was useful and it needed to be developed also in different subjects. As is known, it is very important to give the students feedback in nursing education for the students to evaluate themselves and to realize and correct their deficiencies.

All of the students who participated in the study indicated that it was necessary to use mobile applications in nursing education. In addition, they all stated that rather than alone, it would be more useful to perform the mobile application integratedly with expression, demonstration and laboratory applications used in nursing education (Table 3). Similarly in the study, the nursing students indicated that mobile applications should be added to the traditional education $[6,11]$.

As is known, intraclass teaching enables face-toface interaction between the instructor and student and gives the student to ask the instructor about unclear points and discuss them with her/him while lecturing. Also the demonstration method used in nursing education and laboratory courses where applications are performed on models help the students learn the better with seeing and practising. In nursing education, mobile technologies can be used both in in-classroom and out-of-classroom activities and students can maintain learning activities with mobile applications. Mobile technologies provide the opportunity to follow the games and view the simulations about course materials, current evidence, guidelines, educational videos, and learning [33]. In addition to this; mobile applications, which can be easily used by the students anytime and anywhere without any time limitation, are very important up-to-date teaching strategies that increase the students' knowledge, self-competence, self-confidence and repetition of the subject and reduce their anxiety and stress. Furthermore, students can maintain learning activities independent from the instructor with their mobile phones by using mobile question-answer applications in which educational sharing and discussions are performed.

\section{Conclusions}

According to the results of this study, most of the $1^{\text {st }}$-grade nursing students spent on the internet on their mobile phones; mainly used their phones to talk, socialize, have fun and do their homework; had mobile applications such as Instagram, WhatsApp and YouTube on their phones; and almost all of them used their phones everytime and everywhere. In addition, it was seen that using the mobile application in nursing education increased the students' self-confidence and self-competence and reduced their stress. Besides, the students belive that it will be useful to use both standard teaching method in which the instructor lectures and relevant mobile applications together. In line with these results, it is believed that it will be useful to prepare mobile applications in nursing education, integrate these mobile applications into standard education and revise the curricula accordingly. Furthermore, the results of this study reflect the opinions of first-grade nursing students. Thus, it is suggested to conduct qualitative and quantitative studies on the use of mobile applications in nursing education with nursing students in upper grades.

\section{Authorship Statement}

AKV and MSB design of the study, data collection, analysis, interpretation of data, manuscript drafting and revising. All authors read and approved the final manuscript to be published.

\section{Conflicts of Interest and Source of Funding}

There is no conflict of interest and financial interest in this study. This study was not supported financial.

\section{Acknowledgements}

We would like to thank the students who participated in the study.

\section{References}

1. Cheraghi R, Jasemi M, Namadi F (2019) Effectiveness of the clinical teaching associate model in clinical nursing education. Nursing and Midwifery Studies 8: 132-136.

2. Kim H, Suh EE (2018) The Effects of an interactive nursing skills mobile application on nursing students' knowledge, self-efficacy and skills performance: A randomized con- 
trolled trial. Asian Nurs Res (Korean Soc Nurs Sci) 12: 17 25.

3. Haraldseid C, Friberg F, Aase K (2016) How can students contribute? A qualitative study of active student involvement in development of technological learning material for clinical skills training. BMC Nurs 15: 2.

4. Mackay BJ, Anderson J, Harding T (2017) Mobile technology in clinical teaching. Nurse Educ Pract 22: 1-6.

5. Oermann MH, Muckler VC, Morgan B (2016) Framework for teaching psychomotor and procedural skills in nursing. $J$ Contin Educ Nurs 47: 278-282.

6. Barisone M, Bagnasco A, Aleo G, Catania G, Bona M, et al. (2019) The effectiveness of web-based learning in supporting the development of nursing students' practical skills during clinical placements: A qualitative study. Nurse Educ Pract 37: 56-61.

7. Forehand JW, Miller B, Carter H (2017) Integrating mobile devices into the nursing classroom. Teaching and Learning in Nursing 12: 50-52.

8. Cho S, Lee E (2016) Distraction by smartphone use during clinical practice and opinions about smartphone restriction policies: A cross-sectional descriptive study of nursing students. Nurse Educ Today 40: 128-133.

9. Alsayed S, Bano N, Alnajjar H (2019) Evaluating practice of smartphone use among university students in undergraduate nursing education. Health Professions Education.

10. O'Connor S, Andrews T (2016) Nursing students' opinion on the use of smartphone applications (Apps) in clinical education and training: A study protocol. Stud Health Tehnol Inform 225: 1024-1025.

11. O'Connor S, Andrews T (2018) Smartphones and mobile applications (apps) in clinical nursing education: A student perspective. Nurse Educ Today 69: 172-178.

12. Risling T (2017) Educating the nurses of 2025: Technology trends of the next decade. Nurse Educ Pract 22: 89-92.

13. Kim HJ, Park H (2019) Effects of smartphone-based mobile learning in nursing education: A systematic review and meta-analysis. Asian Nurs Res (Korean Soc Nurs Sci) 13: 20-29.

14. Phillippi JC, Wyatt TH (2011) Smartphones in nursing education. Comput Inform Nurs 29: 449-454.

15. Li C, He J, Yuan C, Chen B, Sun Z (2019) The effects of blended learning on knowledge, skills, and satisfaction in nursing students: A meta-analysis. Nurse Education Today 82: 51-57.

16. Rodder SG, Kindratt TB, Xiao C, Orcutt V, Koch C, et al. (2018) Teaching and evaluating smartphone applications: The effectiveness of a curriculum expansion. Edus Health (Abingdon) 31: 95-102.

17. Shuja A, Qureshi IA, Schaeffer DM, Zareen M (2019) Effect of m-learning on students' academic performance mediated by facilitation discourse and flexibility. Knowledge Management \& E-Learning 11: 158-200.

18. Lall P, Rees R, Law GCY, Dunleavy G, Cotič Ž, et al. (2019) Influences on the implementation of mobile learning for medical and nursing education: Qualitative systematic review by the Digital Health Education Collaboration. J Med Internet Res 21: e12895.

19. Lee H, Min H, Oh SM, Shim K (2018) Mobile technology in undergraduate nursing education: A systematic review. Healthc Inform Res 24: 97-108.
20. Kim SJ, Shin H, Lee J, Kang S, Bartlett RA (2017) A smartphone application to educate undergraduate nursing students about providing care for infant airway obstruction. Nurse Educ Today 48: 145-152.

21. Lee NJ, Chae SM, Kim H, Lee JH, Min HJ, et al. (2016) Mobile-based video learning outcomes in clinical nursing skill education: A randomized controlled trial. Comput Inform Nurs 34: 8-16.

22. Lin YT, Lin YC (2016) Effects of mental process integrated nursing training using mobile device on students' cognitive load, learning attitudes, acceptance, and achievements. Computers in Human Behavior 55: 1213-1221.

23. Jeong $H$ (2017) Effects of nursing students' practices using smartphone videos on fundamental nursing skills, self-efficacy, and learning satisfaction in South Korea. EURASIA J Math Sci Tech Ed 13: 2351-2365.

24. Kang J, Suh EE (2018) Development and evaluation of "chronic illness care smartphone apps" on nursing students' knowledge, self-efficacy, and learning experience. Comput Inform Nurs 36: 550-559.

25. Kim MS, Park JH, Park KY (2012) Development and effectiveness of a drug dosage calculation training program using cognitive loading theory based on smartphone application. J Korean Acad Nurs 42: 689-698.

26. Li KC, Lee LYK, Wong SL, Yau ISY, Wong BTM (2017) Mobile learning in nursing education: Catering for students and teachers' needs. Asian Association of Open Universities Journal 12: 171-183.

27. Polit DF, Beck CT (2018) Essentials of nursing research appraising evidence for nursing practice. ( $9^{\text {th }}$ edn), Wolters Kluwer Health, Philadelphia, 183-213.

28. Taherdoost $H$ (2016) Sampling methods in research methodology; how to choose a sampling technique for research. International Journal of Academic Research in Management 5: 18-27.

29. Nyumba OT, Wilson K, Derrick CJ, Mukherjee N (2018) The use of focus group discussion methodology: Insights from two decades of application in conservation. Methods in Ecology and Evolution 9: 20-32.

30. Damor RB, Gamit PS; Modi A, Patel J, Kosambiya JK (2018) Pattern of smart phone and internet usage among medical students in Surat, Gujarat - a cross sectional study. National Journal of Community Medicine 9: 469-473.

31. Slaih MA, Khader YS, Amarneh BH, Alyahya MS, Al-Adwan NT (2019) Patterns of smartphone use among university students in Jordan. The Editorial Assistants Jordan 30: 5461.

32. Hu Q (2019) Analysis of the application of network education platform in nursing education. International Workshop on Education, Development and Social Sciences, Francis Academic Press, UK, 1476-1480.

33. Şenyuva E (2019) Reflections on nursing education of technological developments. Florence Nightingale Journal of Nursing 27: 79-90. 